\title{
Estudo Projetual em Contêiners para Moradia Estudantil
}

\author{
Design Study on Containers for Student Housing
}

Estudio de Diseño de Contenedores para Alojamiento de Estudiantes

\section{Andréa Holz Pfützenreuter}

Dra. Arquiteta Urbanista, UFSC, Brasil. andrea.hp@ufsc.br

Thainá Kaestner Araujo Engenheira Civil de Infraestrutura, UFSC, Brasil. thaina.kaestner@gmail.com 


\section{INTRODUÇÃO}

John et al. (2002) apud Oliveira et al. (2017), cita que considerando os impactos causados pela construção civil, a partir do descarte indevido dos resíduos e utilização de materiais agressivos ao ambiente, é indispensável buscar soluções inovadoras para o desenvolvimento da sustentabilidade.

As soluções sustentáveis deveriam ser aplicadas desde o início do projeto até a possibilidade de demolição do empreendimento, visto o consumo e geração de resíduos (ARAÚJO, 2009). Segundo Cardoso e Araújo (2006) apud Marques et al. (2017), a etapa de execução é responsável por uma parte significativa dos impactos gerados no ambiente.

Uma construção sustentável otimiza os espaços; integra o meio natural e social, respeitando as características; e prevê o gerenciamento de água, energia e resíduos. A utilização dos recursos naturais como o sol e ventos são diretrizes projetuais de interação do desenvolvimento do projeto à sua localização, a identificação de materiais e sistemas que apresentem uma vida útil longa e de baixa manutenção (COLOMBO; SATTLER; ALMEIDA, 2006).

A utilização de contêiners, na construção, iniciou nos canteiros de obra como um local para armazenagem de materiais, e com passar do tempo foram adaptados de forma arquitetônica para residências (OLIVEIRA et al., 2017). Segundo Romano, Paris e Neuenfeldt Junior (2014), a reutilização dos contêiners para construção civil contribui para a remoção de um resíduo do meio ambiente, gerando uma redução da quantidade destes.

Este artigo tem como objetivo apresentar a elaboração um projeto modular sustentável para moradia estudantil utilizando contêiner; identificar critérios para soluções projetuais de uma construção sustentável otimizando a implantação modular.

Segundo Oliveira et al. (2017), contêiners são produzidos em metal podendo ser usados várias vezes, visto a resistência do material. Após o término de sua vida útil, para o transporte de cargas, cerca de dez anos, são descartados pelas empresas, sendo vendidos para ferros-velhos, parcialmente reciclados ou deixados à deriva no meio ambiente (MILANEZE et al., 2012 apud OLIVEIRA et al., 2017).

\section{CONSTRUÇÕES SUSTENTÁVEIS}

Segundo Leight Neto (2011), o conceito de sustentabilidade influencia as construções quanto à sua integração com o meio sendo variável com o grau de interação aplicado ao projeto. Desta forma as construções bioclimáticas, casas ecológicas e arquitetura sustentável são temas discutidos e importantes.

Para Patzlaff (2009), a sustentabilidade incorpora o uso de recursos renováveis e a redução do uso de energia durante a execução das edificações, mas na fase de utilização também existe um impacto ambiental específico a ser projetado e definido. A manutenção durante a vida útil de um edifício também consome recursos que geram poluição.

Licco (2006) apud Patzlaff (2009) apresenta seis princípios fundamentais para que uma construção seja sustentável:

- Otimização das potencialidades do local: a seleção do local, localização, orientação e o paisagismo que afetam as condições locais, os meios de transporte, serviços e uso de 
energia. O relevo, a presença de cursos d'água e qual a vegetação existente são considerados para que seja causado o mínimo de interferência;

- Otimização do uso de energia: é essencial a redução da demanda e melhora na eficiência da aplicação da energia;

- Proteção e conservação da água: utilização de água tratada de forma eficiente e com consciência, reusando e reciclando quando viável. A captação e aproveitamento de água da chuva deve ser considerado em lavagem de pátios, irrigação de áreas verdes e veículos;

- Utilização de produtos com menor impacto ambiental: nas edificações devem ser utilizados materiais que minimizem os impactos ambientais gerados e perigos a saúde humana, considerando a geração de resíduos, perdas, riscos durante o manuseio e a durabilidade, tendo a saúde e segurança dos trabalhadores e do meio como pontos importantes;

- Garantia de boa qualidade do ar nos ambientes internos: maximizar o uso de luz natural, dispor de ventilação adequada, evitar materiais que emitam compostos voláteis, manter vistas para o exterior e reduzir ruídos;

- Otimização dos processos de operação e manutenção: especificar materiais que necessitem de uma manutenção simplificada e reduzida, com menor consumo de água e energia, que demandem materiais menos tóxicos e em menor quantidade.

Para Macedo (2011), um empreendimento sustentável deve se preocupar com as práticas do projeto, construção e operação, que de alguma forma reduzam, ou até eliminem, os impactos negativos gerados ao meio ambiente e os usuários.

Visando a redução de impactos ambientais, o setor da construção civil incentiva a reutilizar materiais descartados (MILANEZE, 2012). Desta forma, contêiners passaram a ser elementos construtivos desde os anos 1990, quando foram adaptados e utilizados como habitações estudantis, hotéis e escritórios, e residências unifamiliares (OCCHI; ALMEIDA, 2016).

\subsection{Sistema construtivo por contêiner}

Carbonari (2015) conceitua os contêiners são construções metálicas, pré-fabricadas, formadas por perfis e chapas de aço patinável, comumente conhecido como aço Corten, que apresentam alta resistência a corrosão. Os mesmos são utilizados para acomodar e transportar as cargas em longas distâncias, por diversos sistemas de transporte, garantindo a segurança, inviolabilidade e rapidez de manuseio. No mercado são encontrados diversos tipos sendo aplicados em diferentes situações.

Segundo Calory (2015) os contêiners podem ser aplicados na indústria da construção como uma obra permanente ou temporária, tornando-se edifícios residenciais ou áreas de apoio em canteiros de obra. Além do reaproveitamento do material descartado, Nunes e Sobrinho Junior (2017) afirmam que a utilização deste material reduz o uso de recursos naturais que seriam utilizados na construção, o que significa uma obra limpa e com menos entulho. 
Guedes e Buoro (2015) destacam que os contêiners do tipo Dry Box High Cube, são os mais utilizados, devido ao pé direito ser o mais adequado para construções. Ressaltam os autores que um único módulo era suficiente para criação de uma moradia.

Os edifícios em contêiner possuem as mesmas características de construções convencionais e devem seguir os códigos de obras locais. No projeto deve constar todos os cortes com suas devidas dimensões, indicando a localização dos reforços, pontos de ligação, instalações elétricas e hidráulicas. $\mathrm{O}$ contêiner é um sistema composto por várias partes que formam um todo, sendo estas dependentes entre si, ou seja, sua resistência depende das partes que constituem o mesmo, por este motivo quando qualquer um dos constituintes for alterado ou retirado, a resistência é comprometida. Desta forma, dependo do caso, são necessários reforços estruturais, em aberturas ou na estrutura em geral (CALORY, 2015).

Fernandes (2009) destaca que para a implantação da edificação, a escolha do terreno deve ser o primeiro fator de definição do projeto. Ao verificar suas características como forma, orientação, topografia, presença de massa de água e vegetação, define-se a forma da edificação e os materiais que serão incorporados em fachadas, fechamentos e aberturas. 0 autor ainda comenta que as aberturas, devem ser pensadas para integrar a iluminação natural e artificial para redução de gastos energéticos, e verificando as orientações e velocidades dos ventos para garantir maior conforto nos ambientes internos.

Conforme Lara (2014), no Brasil, recomenda-se que as áreas privativas de quartos, recebam o sol da manhã, ou seja, orientação leste ou nordeste, para apresentarem temperaturas mais agradáveis no período da noite. $\mathrm{O}$ sol da tarde, passado o meio dia, gera aquecimento nos ambientes que incide. Ambientes ao sul recebem pouca ou quase nenhuma incidência solar. $A$ ocorrência de mofo e umidade é comum nas regiões mais úmidas, como no município de Joinville.

Além de recursos naturais, recursos técnicos podem ser utilizados para melhorar o conforto das edificações, como brises, isolamentos e o emprego de materiais e cores (FRICKE, 1999).

A cobertura pode ser utilizada como aliada para melhorar o conforto térmico, acústico, redução do uso de energia e até mesmo a estética da construção. O telhado verde é uma alternativa sustentável quando comparada aos telhados convencionais e lajes, gerando melhoria no desempenho térmico (NASCIMENTO, 2010 APUD HENN E CALIGARI, 2016).

Telhados brancos também são uma opção para gerar melhoria no conforto térmico em edificações. Esta técnica tem como objetivo reduzir o consumo de energia para resfriamento e aquecimento, visto os raios serem refletidos e o calor não ser absorvido, permitindo a redução de até 30\% da temperatura dos ambientes (SIQUEIRA, 2014).

$\mathrm{O}$ isolamento térmico tem a função principal de reduzir o gasto com energia ou até mesmo suprir a necessidade de equipamentos para resfriamento ou aquecimento (NAVROSKI et al., 2010). Segundo o autor, opções como poliestireno expandido (EPS), madeira e casca de arroz podem ser usadas em diferentes casos, sendo o EPS a solução com melhor desempenho térmico no Brasil. A lã de politereftalato de etileno (PET), material fabricado por meio da reciclagem de garrafas plásticas descartadas, pode substituir a lã de vidro ou de rocha, tendo desempenho térmico superior e pode ser uma opção mais sustentável (BARBOSA et al., 2016). 


\section{DESENVOLVIMENTO DE PROJETO}

Para o desenvolvimento do projeto foram definidas diretrizes projetuais baseadas nos seis princípios fundamentais para uma construção sustentável:

- Terreno: sendo avaliada localização, orientação em relação à Norte-Sul, topografia, presença de vegetação e entorno;

- Gerenciamento de energia: aproveitamento de luz e ventilação natural;

- Gerenciamento de água: captação de água da chuva;

- Materiais: reaproveitamento de materiais descartados, materiais que melhorem as condições térmicas e acústicas;

- Otimização do espaço da construção.

O município de Joinville está localizado na região norte do Estado de Santa Catarina, região Sul do Brasil. Por ser um município que possui dezoito instituições de nível superior, recebe estudantes de outros estados para residir durante sua graduação e permanecer nesse período. O critério relevante de escolha para o bairro foi a proximidade da UFSC Campus de Joinville, realizando algumas análises para sua a seleção: avaliação do zoneamento dos bairros, verificação dos bairros que não são atingidos pelas inundações, avaliação da renda e buscar por terrenos disponíveis para construção da moradia.

Para compatibilizar esses fatores foram confeccionados 4 mapas: município em bairros, zoneamento, inundação e renda. Utilizou-se o software QGIS, com os dados obtidos no Sistema de Informações Georreferenciadas (SIMGeo, 2018) do município; e da edição de 2017 das publicações da Secretaria de Planejamento Urbano e Desenvolvimento Sustentável (SEPUD, 2017).

Através do mapa de inundações identificou-se que dos quarenta e três bairros do município apenas quatorze não eram atingidos quando ocorriam as inundações. Quanto ao mapa de zoneamento, foram identificados, nos quatorze bairros restantes, setores de adensamento primário, secundário e controlado, setor de interesse de conservação de várzeas, especial de centralidade urbana e de proteção ambiental. Segundo a Lei de Ordenamento Territorial (LOT), todas as seções permitem a construção de residências multifamiliares, sendo que para cada caso existem orientações específicas.

Ao analisar os quatorze bairros com relação a proximidade à UFSC, os bairros Jardim Sofia e Pirabeiraba foram identificados para avaliar a distância rodoviária a ser percorrida até a universidade e tempo gasto até o local utilizando transporte público. Do bairro Jardim Sofia até a UFSC Joinville, são aproximadamente 10 quilômetros percorridos, e utilizando transporte público o tempo gasto é próximo de uma hora. Do bairro Pirabeiraba até a universidade percorre-se 7,6 quilômetros e o tempo do percurso do transporte público é em torno de 35 minutos. Desta forma, optou-se pelo bairro Pirabeiraba para o projeto. 


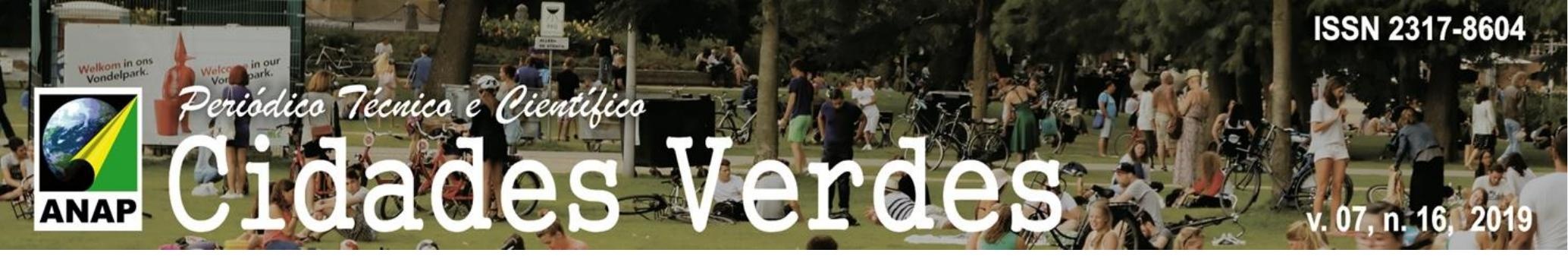

\subsection{Terreno}

Com o público alvo sendo estudantes, a proximidade a comércios e serviços, como supermercados, padarias e farmácias, e acesso ao transporte público é indispensável. Desta forma a limitação para o trabalho foi a região central do bairro de Pirabeiraba, visto ser a região de concentração destes serviços.

A busca por terrenos vazios foi realizada no SIMGeo em conjunto com o Google Maps, visando identificar a divisão dos lotes, área, zoneamento e serviços do local. Ao identificar mais de 10 terrenos, estes foram classificados e comparados pela proximidade a comércios e serviços.

Adotando o princípio sustentável de otimização das potencialidades do local como critério, os terrenos com grandes áreas verdes foram descartados para o projeto.

O terreno escolhido para a implantação do projeto apresenta confrontantes suscetíveis ao projeto bioclimático e com uma área de $967 \mathrm{~m}^{2} ; 19,85$ metros de frente, 46,66 metros lateral na lateral esquerda, 49,81 metros na lateral direita e 21,23 metros de fundos, permite sua plena ocupação.

\subsection{Programa e Projeto arquitetônico}

Ao programa de necessidades destinado a moradia estudantil foram estabelecidos os ambientes necessários para as atividades cotidianas como comer, dormir, estudar, tomar banho e estar. Considerando duas possibilidades: moradia para um e para dois estudantes.

A moradia para um e dois estudantes resultou em $12,10 \mathrm{~m}^{2}$ e $19,40 \mathrm{~m}^{2}$ de área total, respectivamente, considerando as áreas de mobiliário e circulação necessária nos ambientes. O contêiner possui área de $14,76 \mathrm{~m}^{2}$, sendo este valor considerado para o projeto de cada um dos módulos.

Com a diretriz de otimizar a utilização dos contêiners do tipo Dry Box High Cube de 20 pés, foi definido o projeto arquitetônico da moradia para um e dois estudantes (Figura 1). 


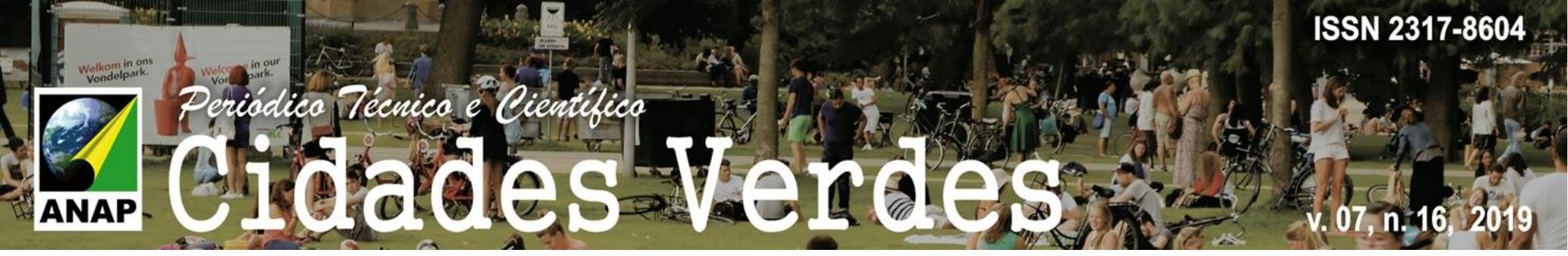

Figura 3: Opções de layout - moradia para dois estudantes

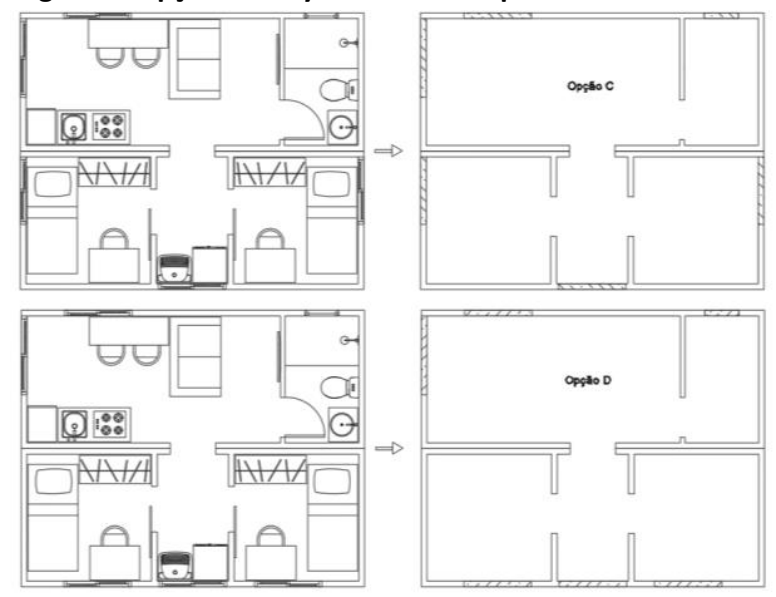

Fonte: AUTORA, 2019.

Após a definição de todos os itens anteriormente apresentados, foi realizado estudo da implantação da moradia no lote. Para isso, foram respeitados os recuos mínimos estabelecidos na LOT, Lei Complementar 470/2017, sendo o recuo frontal mínimo de cinco metros entre a linha frontal do imóvel e o alinhamento predial, e no mínimo um metro e cinquenta centímetros de recuos laterais.

Consultando o Anexo VII da Lei Complementar 470/2017, verificou-se que o gabarito máximo permitido no zoneamento é quinze metros de altura. Optou-se por moradias térreas para garantir que não interfeririam na insolação das demais construções, pois as residências próximas possuem no máximo dois pavimentos, e para priorizar o bom aproveitamento do solo e recursos naturais.

Para avaliar as possibilidades de posicionamento das unidades no terreno e o número máximo de moradias suportadas pelo mesmo, o lote foi dividido em seções, da largura dos módulos, seguindo o formato original do terreno e respeitando os recuos antes citados.

A vegetação presente no terreno foi removida por ser de natureza frutífera, sendo restabelecida a arborização após a definição da implantação.

Primeiro foram estudadas as quantidades de moradias para um e para dois estudantes. $\mathrm{Na}$ sequência foram mesclados os dois modelos. Em todos os casos foi respeitado o espaçamento de três metros entre unidades, recomendação da legislação do município. Como resultado de estudo surgiram mais de 15 variações de implantação.

A Tabela 1 resume as áreas resultantes das três opções de disposição no terreno. 
Tabela 1: Resumo da análise 1

\begin{tabular}{cccccccc}
\hline Opção & $\begin{array}{c}\text { Tipo de } \\
\text { moradia }\end{array}$ & Quantidade & $\begin{array}{c}\text { Número } \\
\text { de } \\
\text { moradores }\end{array}$ & $\begin{array}{c}\text { Área } \\
\text { aproximada } \\
\text { entre moradias } \\
\left(\mathbf{m}^{\mathbf{2}}\right)\end{array}$ & $\begin{array}{c}\text { Área total } \\
\text { do terreno } \\
\left(\mathbf{m}^{\mathbf{2}}\right)\end{array}$ & $\begin{array}{c}\text { Área } \\
\text { construída } \\
\left(\mathbf{m}^{\mathbf{2}}\right)\end{array}$ & $\begin{array}{c}\text { Área } \\
\text { permeável } \\
\left(\mathbf{m}^{\mathbf{2}}\right)\end{array}$ \\
\hline 1 & A & 15 & 15 & 45,00 & 967,44 & 221,43 & 746,01 \\
2 & D & 10 & 20 & 45,00 & 967,44 & 295,24 & 672,20 \\
3 & A & 8 & 18 & 44,00 & 967,44 & 265,72 & 701,72 \\
\hline
\end{tabular}

Fonte: AUTORA, 2019.

Nessa primeira etapa, apenas a quantidade de unidades foi objeto de estudo. Quando se trata de sustentabilidade, estas podem não ser as melhores soluções. Outras configurações foram estudadas, verificando a disposição que garantiria os espaços entre as edificações que promovam circulação de ar, menor interferência do sombreamento entre moradias e possibilidade de utilização dessas áreas para lazer ou áreas verdes.

A Tabela 2 apresenta o resumo das áreas resultantes da disposição no terreno.

Tabela 2: Resumo da análise 2

\begin{tabular}{cccccccc}
\hline Opção & $\begin{array}{c}\text { Tipo de } \\
\text { moradia }\end{array}$ & Quantidade & $\begin{array}{c}\text { Número } \\
\text { de } \\
\text { moradores }\end{array}$ & $\begin{array}{c}\text { Área } \\
\text { aproximada } \\
\text { entre moradias } \\
\left(\mathbf{m}^{2}\right)\end{array}$ & $\begin{array}{c}\text { Área total } \\
\text { do terreno } \\
\left(\mathbf{m}^{\mathbf{2}}\right)\end{array}$ & $\begin{array}{c}\text { Área } \\
\text { construída } \\
\left(\mathbf{m}^{\mathbf{2}}\right)\end{array}$ & $\begin{array}{c}\text { Área } \\
\text { permeável } \\
\left(\mathbf{m}^{\mathbf{2}}\right)\end{array}$ \\
\hline 1 & A & 16 & 16 & 50,00 & 967,44 & 236,19 & 731,25 \\
2 & D & 8 & 16 & 80,00 & 967,44 & 236,19 & 731,25 \\
3 & A & 8 & 16 & 90,00 & 967,44 & 236,19 & 731,25 \\
\hline
\end{tabular}

Fonte: AUTORA, 2019.

Comparando os dados das Tabelas 1 e 2, a quantidade de moradias nas opções apresentadas nas análises são parecidas, não havendo mudanças quanto a quantidade de moradias que podem ser instalados. Entretanto, na análise 2, observa-se que as áreas entre moradias promovem espaçamentos maiores e consequentemente melhor aproveitamento desses espaços.

Na opção um (Figura 4), com residências para um estudante, optou-se por posicionar duas moradias juntas, formando um " $\mathrm{L}$ ", essa combinação gerou melhor encaixe entre os módulos no terreno, aumentando as áreas para circulação. As interferências das sombras das edificações são menores, permitindo uma boa insolação nos conjuntos e adensamento. Porém, em algumas moradias a incidência solar nos quartos é pequena. 


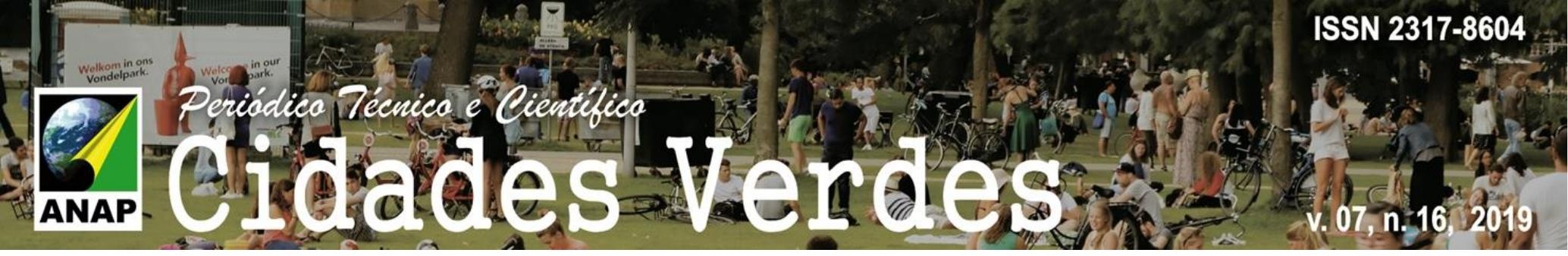

Figura 4: Sombreamento - opção 1

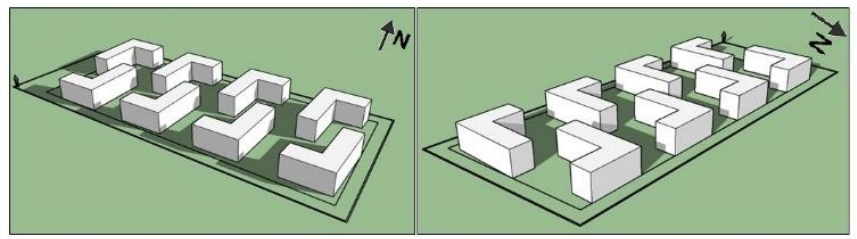

Fonte: AUTORA, 2019.

No caso da opção dois (Figura 5), as mesmas foram alocadas lado a lado formando um "S". Quanto ao sombreamento, a interferência das sombras entre residências é semelhante ao caso anterior, com a diferença que nesse caso todos os dormitórios recebem a luz da manhã (leste).

Figura 5: Sombreamento - opção 2

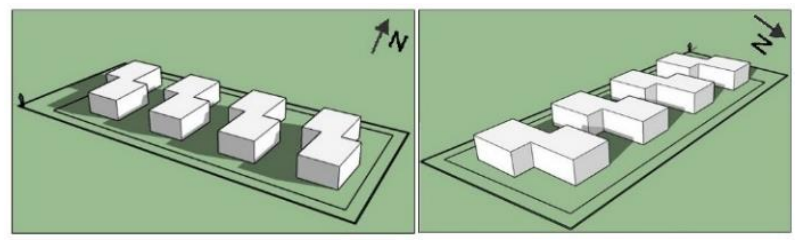

Fonte: AUTORA, 2019.

A última opção é a mescla entre dois tipos de residência, opção A e D. Na opção três (Figura 6), uniu-se dois módulos individuais e um duplo para formar um " $\mathrm{T}$ ". O sombreamento gerado é quase nulo, quando comparado as opções anteriores, mas alguns dormitórios não recebem luz solar, devido a orientação solar, retornando o problema encontrado na opção um.

Figura 6 - Sombreamento - opção 3

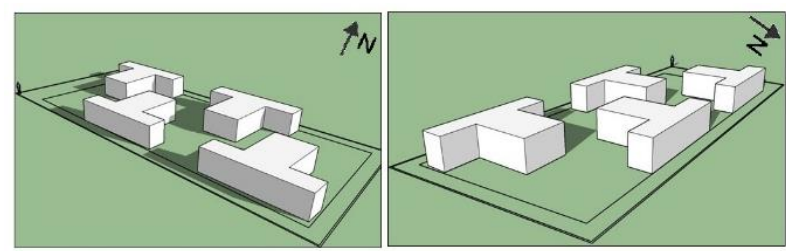

Fonte: AUTORA, 2019.

Quanto a avaliação de sombreamento, nenhum dos casos é ruim. Porém, quando se trata de insolação em ambientes, a primeira e a terceira opção não permitem que todos os módulos recebam a luz solar. Algumas moradias recebem insolação direta apenas ao final do dia e outros somente no início do dia. Na opção dois, esse problema não acontece, pois todos as moradias recebem igualmente a insolação em todos os períodos, sendo esta a solução adotada e utilizada para as demais análises projetuais. 
ISSN 2317-8604

\section{3 Índices para implantação}

A Lei Complementar 470/2017, aponta que seria necessário disponibilizar uma vaga de garagem para cada unidade familiar. Entretanto por se tratar de um projeto especial de caráter multifamiliar para estudantes, com o preceito de integrar a sustentabilidade e a utilização de meios de transporte coletivos e ativos, optou-se por adicionar algumas vagas de uso comum na proporção de uma vaga por conjunto, sendo este formado por duas residências.

As quatro vagas de estacionamento foram posicionadas na testada do terreno, nas periferias. Esta configuração permitiu que a entrada para pedestres e ciclistas ficasse centralizada e evidente. Um bicicletário, com capacidade para quatorze bicicletas, pode ser utilizado tanto pelos moradores quanto por visitantes, está disposto na entrada do condomínio.

É importante a verificação dos índices urbanísticos como taxa de ocupação (TO), taxa de permeabilidade (TP) e coeficiente de aproveitamento do lote (CAL), em concordância com os especificados pela LOT. Os resultados dos cálculos dos índices são apresentados na Tabela 3.

Tabela 3: Índices urbanísticos

\begin{tabular}{|c|c|c|c|c|}
\hline Índice Urbanístico & Equação & $\begin{array}{l}\text { Valor } \\
\text { mínimo }\end{array}$ & $\begin{array}{l}\text { Valor } \\
\text { máximo }\end{array}$ & $\begin{array}{c}\text { Valor } \\
\text { Calculado }\end{array}$ \\
\hline Taxa de ocupação & Área do $1^{\mathrm{o}}$ pavimento + área projetada & - & $60 \%$ & $25 \%$ \\
\hline (TO) & Área total do lote & & $00 \%$ & $25 \%$ \\
\hline $\begin{array}{c}\text { Taxa de } \\
\text { permeabilidade (TP) }\end{array}$ & $\mathrm{TP}=\frac{\text { Área permeável }}{\text { Área total do lote }}$ & $20 \%$ & - & $75 \%$ \\
\hline $\begin{array}{c}\text { Coeficiente de } \\
\text { aproveitamento do } \\
\text { lote }(C A L)\end{array}$ & $\mathrm{CAL}=\frac{\text { Área total construída }}{\text { Área total do lote }}$ & - & 2 & 0,24 \\
\hline
\end{tabular}

Fonte: AUTORA, 2019.

\section{PROJETO}

A implantação final é apresentada na Figura 12. 


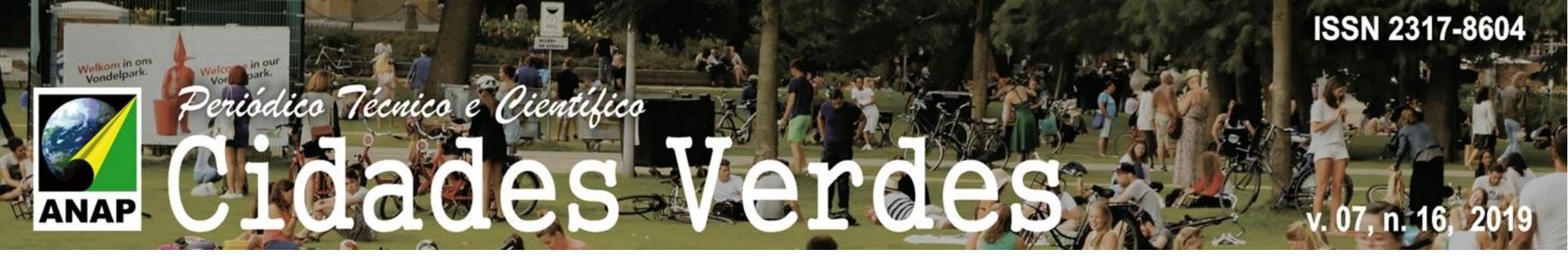

Figura 12: Implantação final

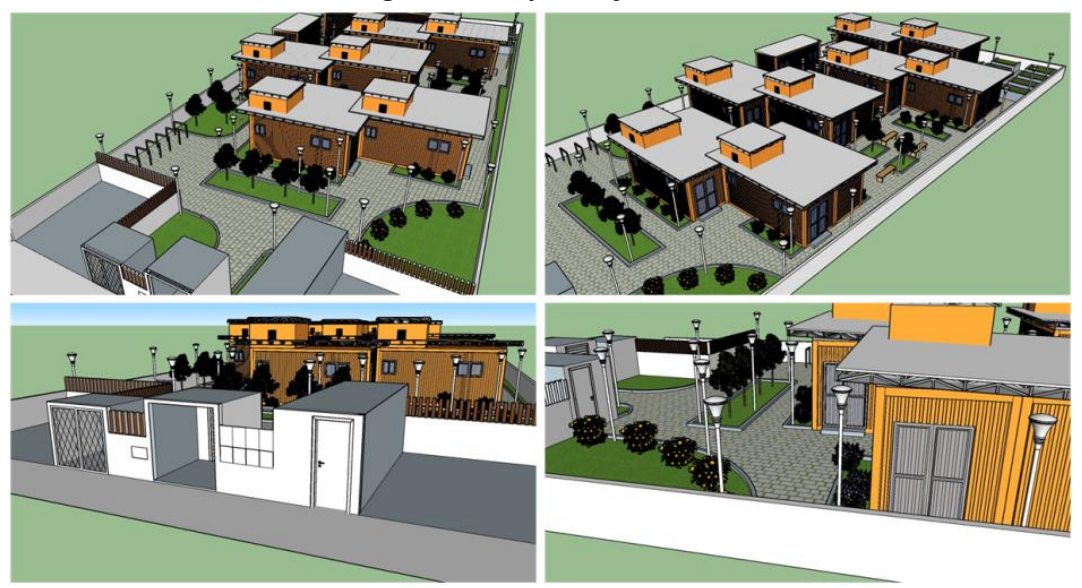

Fonte: AUTORA, 2019.

As calçadas estão afastadas das moradias em um metro, por meio de vegetação arbustiva mantendo a privacidade dos estudantes. O material aplicado nas calçadas é o piso do tipo Concregrama, permitindo a permeabilidade da água e a segurança no deslocamento em dias de chuva. Nas áreas adjacentes as moradias, será aplicada gramínea não afetando a taxa de permeabilidade do lote.

As áreas originadas entre as moradias foram destinadas a descanso, com bancos e árvores frutíferas; e área de lazer ou de estudos em grupo. A área mais ao fundo é destinada a horta e árvores frutíferas com o intuito de estimular os estudantes a aproveitarem os recursos disponíveis, adquirirem ou manterem hábitos saudáveis em sua alimentação, além do fator terapêutico.

Optou-se por não instalar um reservatório principal para armazenamento da água pois, nesse caso, seria necessário a instalação de um conjunto de bombas de recalque para transportar a água até as residências, sendo esse um gasto de energia a ser evitado. Para determinar o volume do reservatório a ser instalado em cada moradia, é necessário estimar qual o consumo por dia. O valor adotado é de 150 litros por dia por pessoa ${ }^{1}$. Sendo assim, considerando dois moradores e que o reservatório deve suprir as necessidades da moradia por dois dias caso ocorra falta de abastecimento, o volume necessário é de 600 litros. Como no mercado não se encontra essa opção, o reservatório proposto é o de 750 litros.

Considerando que, para a rega de jardins, são necessários 1,5 litros $^{2}$ por $\mathrm{m}^{2}$, e que se tem aproximadamente $300 \mathrm{~m}^{2}$ de área verde, estima-se que sejam necessários 450 litros de água, para este fim, por dia. Não existe a necessidade de realizar essa atividade todos os dias, podendo esta ser feita a cada dois ou três dias. Em épocas de poucas chuvas, haverá a necessidade de uso de água potável para fins de irrigação.

O bairro de instalação do projeto ainda não possui cobertura de rede de esgoto, adotando como diretriz projetual o conjunto fossa e filtro como sistema de tratamento de esgoto, promovendo o pré-tratamento do efluente gerado.

\footnotetext{
${ }^{1}$ Valor estimado para residências, segundo Mattos (2016).

${ }^{2}$ Segundo Mattos (2016).
} 
A área para depósito do lixo conta com cinco coletores distribuídos em: duas lixeiras para materiais orgânicos e uma para cada tipo de material reciclável: papeis e plásticos, metais, vidro e outros materiais como lâmpadas, pilhas e óleo de cozinha. O acesso pelos moradores ocorre pela parte interna do condomínio e pelos coletores pela porta externa.

O abastecimento de gás será realizado por meio de central de gás, localizada na testada do lote, sendo acessada apenas pela parte de fora do condomínio facilitando o abastecimento. As dimensões seguem as especificações das normas vigentes (IN 08 - Instalação de Gás Combustível (GLP \& GN)).

\subsection{Memorial descritivo}

Este tópico tem como objetivo apresentar as decisões de projeto da moradia, apresentar materiais utilizados e suas especificações:

- Topografia: o lote não precisa de ajuste de topografia, as movimentações de terra ocorrerão nas etapas de fundação e instalação do sistema de drenagem, o qual aplicará a manta geotêxtil, que impede a passagem de materiais finos; e agregados tipo brita 2 ou 3;

- Fundação: esta etapa é precedida de sondagens para obtenção do perfil estratigráfico do terreno. O lote de projeto não possui esse perfil. Desta forma, optou-se por utilizar fundação rasa do tipo sapata isolada devido à baixa carga imposta pela estrutura, visto esta ser mais leve estruturas convencionais. Ressaltando que não foi realizado projeto de fundação, apenas indicado, sendo estimada as dimensões e quantidade de materiais empregados nas fundações.

- Estrutura: como o contêiner apresenta estrutura de aço com interdependência entre seus componentes, foram aplicados reforços na parede da porta de entrada do módulo cozinha, sala e banheiro; e nas janelas de ambos os módulos. Os recortes nos painéis são realizados para a instalação das esquadrias de acordo com o projeto. Os reforços são de perfis metálicos comerciais, como perfil I, H ou C. A aplicação dos perfis é feita com o intuito de evitar deformação das vigas ou torção da estrutura, desta forma não há necessidade de aplicação de perfis robustos. É importante destacar que não foram realizados os cálculos estruturais;

- Paredes e vedação: o sistema selecionado para as paredes e vedações foi do tipo Drywall. O sistema é composto por: guias e montantes de $48 \mathrm{~mm}$, sendo os montantes espaçados a cada $600 \mathrm{~mm}$ no máximo; placas de gesso acartonado, sendo as brancas para as áreas secas e as verdes (resistentes a umidade) para áreas molhadas; e parafusos de fixação, fita de papel e massa de tratamento de junção. Como isolamento térmico e acústico optou-se pela lã de PET de $50 \mathrm{~mm}$, instalado nos espaçamentos entre montantes;

- Piso: antes da instalação do piso é necessário que seja removido e substituído o assoalho do contêiner. Deve ser aplicada a massa niveladora, composta pela mistura de cimento e cola PVA, sobre o novo assoalho. Na sequência, é aplicada a cola para piso e são instaladas as placas de $3 \mathrm{~mm}$ do piso vinílico. 
- Instalações hidráulicas: as tubulações são instaladas antes da aplicação das placas de gesso acartonado. Utiliza-se tubulação de PVC do tipo soldável para água fria e esgoto. Foi realizada uma estimativa das instalações para elaboração da planilha de custos.

- Instalações elétricas: os eletrodutos e passagens são instalados antes da aplicação das placas de gesso, sendo os eletrodutos de PVC flexível e os condutores de cobre. Assim como o item anterior, foi realizada uma estimativa das instalações para elaboração da planilha de custos.

- Esquadrias: as esquadrias selecionadas para o projeto são: porta de entrada: porta de correr de alumínio $(140 \times 120)$ com duas folhas (1 folha fixa e 1 móvel); dormitórios: porta de madeira de correr (80x210); janela de alumínio de correr $(120 \times 70)$ com duas folhas (1 folha fixa e 1 móvel); banheiro: porta de madeira de correr embutida (90x210); janela de alumínio (70x70) maxim-ar; e as demais janelas são de alumínio de correr (120x70) com duas folhas (1 folha fixa e 1 móvel).

- Cobertura: composta por telhas metálicas do tipo termo acústicas, de perfil trapezoidal, com $40 \mathrm{~mm}$ de espessura. Optou-se por telhas na cor branca, visando a implantação de coberturas brancas, que auxiliam no conforto térmico da edificação. A estrutura também é metálica, composta por perfis laminados ou soldados, sendo estes conectados de forma compatível com a sua resistência e devem ser detalhados pelo projetista responsável. A estrutura aplicada é do tipo treliçada.

- Pintura externa: a parte externa do contêiner deve ser limpa, utilizando detergente biodegradável, para remoção de materiais que podem interferir na pintura. Na sequência é removida qualquer corrosão presente nas chapas, limpando e gerando rugosidade para melhor aderência da tinta. Depois é aplicada a tinta anticorrosiva. ${ }^{3}$

\section{RESULTADOS}

A implantação selecionada é composta por quatro conjuntos de duas moradias cada, ocupando $25 \%$ da área total do terreno. A taxa de ocupação do lote poderia ser em torno de 2,4 vezes maior que a alcançada. Para atingir esse valor máximo, as áreas livres seriam reduzidas, a quantidade de moradias aumentaria, mas os critérios de sustentabilidade seriam suprimidos.

As moradias implantadas abrigam dezesseis estudantes. A disposição das moradias gera pouca sombra entre as mesmas, garantindo a luz solar em todos os períodos do dia sem interferência das demais. O espaço destinado para circulação de pedestres é de 1,20 metros entre as moradias. Segundo a NBR 9050 (ABNT, 2015), que descreve sobre acessibilidades a edificação, mobiliário, espaços e equipamentos urbanos, essa é a largura mínima livre para o passeio.

Por exigência das normas no município, foi necessária a instalação de vagas de estacionamento no condomínio, mesmo que o enfoque do projeto não seja incentivar o uso desse tipo de transporte. Indicando o modo operacional sustentável de compartilhamento de caronas, todos os moradores poderiam compartilhar deste modo de transporte em dia de

\footnotetext{
${ }^{3}$ Sugestões de Minha Casa Container (2019).
} 
chuva, caso não queiram utilizar o transporte público coletivo. A quantidade de vagas disponibilizadas para os transportes ativos é 3,5 vezes maior que aos veículos individuais.

Os princípios fundamentais para uma construção sustentável foram avaliados e tornaram-se diretrizes para o desenvolvimento do projeto, sendo essas aplicadas:

- Gerenciamento de energia: foi aplicado para melhorar o aproveitamento da luz e ventilação natural. Através da introdução de aberturas em todos os ambientes foi possível abranger $18 \%$ da área dos dormitórios, 52\% para a lavanderia e $46 \%$ para cozinha, sala de estar e jantar;

- Gerenciamento de água: para a captação da água da chuva, sendo essa reaproveitada para fins não potáveis, foram instaladas duas cisternas de 600 litros, sendo esse volume suficiente para rega de aproximadamente $800 \mathrm{~m}^{2}$ de área verde. A implantação possui $31 \%$ de área verde, cerca de $300 \mathrm{~m}^{2}$. O volume excedente não utilizado pode ser aplicado em outras atividades;

- Terreno: verificou-se que o local de implantação estava no zoneamento setor especial de centralidade urbana, que permite a construção de residências multifamiliares; e todos os índices urbanísticos foram cumpridos. A orientação em relação a Norte-Sul das moradias permitiu que os dormitórios ficassem direcionados para o leste, aproveitando o sol da manhã. Além disso, todos os ambientes recebem luz solar independente do período do dia. É importante mencionar que o lote está localizado na cota vinte, sem presença de elevações, sendo assim, está em uma região plana. Foram adicionadas vegetações arbustivas, rasteira e frutífera com diferentes funções. Constatou-se que a vizinhança é predominantemente residencial e comercial;

- Otimização do espaço da construção: com apenas um módulo foi possível criar uma moradia estudantil. Unindo-se dois módulos é possível atender dois estudantes;

- Materiais: o reaproveitamento foi aplicado pela utilização de contêiners Dry Box 20 pés descartados após o final da sua vida útil para qual foi projetado (10 anos). Aplicação de lã de PET de 50mm teve como objetivo melhorar o conforto térmico e acústico dos ambientes. Por estar localizado em região plana, o lote não necessita de ajustes de topografia. Para fundação optou-se por sapata isolada. A estrutura deve ser reforçada com perfis metálicos para evitar deformações. Para paredes e vedações o sistema de Drywall. As instalações hidráulicas e elétricas são aplicadas internas as paredes para proteção das instalações. Para as esquadrias optou-se por metálicas e de madeira. A estrutura de cobertura é metálica, sendo esta aplicada em conjunto com telhas metálicas com camada especial de isolamento térmico e acústico. Para evitar corrosões futuras e problemas na estrutura, a parte externa dos módulos deve receber tinta anticorrosiva.

As vegetações adicionadas no condomínio possuem diferentes funções. As arbustivas objetivam gerar maior privacidade nas moradias devido à proximidade das janelas e criando uma sensação de barreiras visuais e o abafamento do som externo à moradia com maiores volumes

Com a função de vegetação alta, as árvores frutíferas foram incluídas em diversas áreas do condomínio. Estas impedem a passagem da luz solar, de forma parcial, evitando o 
aquecimento excessivo da moradia. A vantagem das árvores frutíferas é a disponibilidade de seus frutos para consumo. Entretanto, deve-se ter cuidado com a escolha deste tipo de vegetação, pois algumas espécies atingem alturas superiores a dois metros, e podem danificar as estruturas próximas a elas, além de exigirem cuidados especiais diferentes de outros tipos de árvores. É importante se atentar que independentemente do tipo selecionado a vegetação deve ser nativa, evitando comprometer a biodiversidade local.

As gramíneas dos canteiros e outras áreas do condomínio tem como função principal facilitar a infiltração de água no solo. A manutenção exige cortes regulares para evitar a sensação de falta de limpeza do condomínio. A vegetação proporciona uma sensação agradável, pacificadora, reduzindo o stress e ansiedade, colaborando com o paisagismo.

Com apenas um contêiner de 20 pés com $14,76 \mathrm{~m}^{2}$ é viável a construção de uma moradia. Para o projeto com dois contêiners o custo total é $\mathrm{R} \$ 58.555,16$, sendo $\mathrm{R} \$ 1.983,57$ por metro quadrado. Para o levantamento do mesmo, foram desenvolvidas quatro planilhas, divididas em: módulo cozinha, sala e banheiro, e módulo dormitório e lavanderia, custos estimados e da moradia completa.

O custo dos módulos cozinha, sala e banheiro, e dormitório e lavanderia englobam cerca de $72 \%$ do custo total, mostrando que, o sistema construtivo por si próprio, somado aos acabamentos, tem a maior contribuição no total. Os demais custos, tem contribuição de $28 \%$, sendo que estes podem sofrer maiores variações quando comparados aos anteriores, visto não possuírem projetos, no caso das instalações e fundações, e não foram detalhados, no caso da cobertura.

Para comparação com o metro quadrado da construção convencional, utilizou-se o custo unitário básico (CUB). Este valor não inclui os custos das fundações, projetos, aquisição do terreno e outros itens, como paisagismo ou serviços complementares. O valor do CUB para o mês de abril de 2019 é R\$ 1.848,59 por metro quadrado. Sendo assim, é necessário verificar qual o custo total do sistema em contêiner, desconsiderando as fundações. O Quadro 13 apresenta a área total do projeto, o custo total da moradia e por metro quadrado.

\begin{tabular}{lccc}
\multicolumn{4}{c}{ Tabela 8: Comparação de custos } \\
\hline Sistema & $\begin{array}{c}\text { Área total } \\
\left(\mathbf{m}^{\mathbf{2}}\right)\end{array}$ & $\begin{array}{c}\text { Custo total da } \\
\text { moradia }\end{array}$ & Custo/ $\mathbf{m}^{\mathbf{2}^{4}}$ \\
\hline $\begin{array}{l}\text { Alvenaria } \\
\text { convencional }\end{array}$ & 29,52 & $\mathrm{R} \$ 54.570,38$ & $\mathrm{R} \$ 1.848,59$ \\
Contêiner & 29,52 & $\mathrm{R} \$ 51.809,08$ & $\mathrm{R} \$ 1.755,05$ \\
\hline
\end{tabular}

Fonte: AUTORA, 2019.

Observa-se que o custo da residência, com o sistema em contêiner, gera cerca de $5 \%$ de economia quando comparado ao sistema convencional. Destaca-se que não houve o levantamento dos custos referente a mão de obra.

Se para o sistema de contêiner a mão de obra for especializada para sua execução, o custo da moradia pode se tornar mais elevado, reduzindo ou excluindo a economia gerada. Entretanto,

\footnotetext{
${ }^{4}$ Desconsiderando a fundação
} 
o sistema convencional gera maior quantidade de resíduos e desperdício de materiais, elevando em até $30 \%$ os custos da construção. Deste modo, quando comparado ao sistema de contêiner, que gera como resíduo os recortes dos painéis, assoalhos removidos e pequenas sobras dos acabamentos, o sistema convencional pode se tornar um sistema mais caro devido à grande quantidade de resíduos e desperdício gerados

A implantação completa é composta por 4 conjuntos, sendo o custo total, baseado no custo de um único conjunto, de $\mathrm{R} \$$ 450.505,24.

\section{CONCLUSÃO}

Com o objetivo principal de elaborar um projeto modular sustentável utilizando o sistema construtivo de contêiner. O desenvolvimento do projeto foi baseado em seis princípios fundamentais para uma construção sustentável, sendo eles: o terreno de implantação, verificando zoneamento, confrontantes e topografia; sistemas de gerenciamento de água e energia, visando o melhor aproveitamento dos elementos naturais; reutilização de materiais descartáveis e materiais que melhorem conforto térmico e acústico da edificação; e otimização do espaço, objetivando o melhor aproveitamento de área da moradia.

Com o intuito de otimizar o espaço disponível em um contêiner de 20 pés, foi desenvolvida a moradia para um estudante, que atendeu as necessidades mínimas estipuladas, desenvolvendo-se assim uma residência em módulo único. A segunda configuração demonstra a versatilidade do sistema, ou seja, que se pode desenvolver módulos padronizados e que quando acoplados formam a moradia para um grupo maior de pessoas. Neste trabalho estudou-se o caso para dois estudantes, visando a utilização da menor quantidade possível de contêiners.

Pelo desenvolvimento de planilhas de custos, verificou-se que a construção da moradia, para dois estudantes, tem custo total $5 \%$ menor que uma construção em sistema de alvenaria convencional.

O projeto sustentável desenvolvido aplicou cisternas para captação e armazenamento de água da chuva para fins não potáveis; adicionou diversos tipos de vegetação nas áreas comuns do condomínio, colaborando com a infiltração de água no solo, paisagismo e conforto térmico; implantou uma horta com o intuito de aproveitar o espaço livre resultante disposição das residências e incentivar o melhor aproveitamento dos recursos naturais; e buscou otimizar o espaço interno das moradias.

Como sugestão para trabalhos futuros recomenda-se o estudo dos tipos de fundação a serem aplicadas no sistema construtivo; desenvolvimento do projeto complementar de captação de água da chuva; análise estrutural dos contêiners e o dimensionamento dos reforços.

\section{REFERÊNCIAS BIBLIOGRÁFICAS}

ASSOCIAÇÃO BRASILEIRA DE NORMAR TÉCNICAS. NBR 9050: acessibilidade a edificação, mobiliário, espaços e equipamentos urbanos. Rio de Janeiro, 2015.

BARBOSA, Daniele Rezende et al. Isolamento térmico. In: V SEMINÁRIO INTERNACIONAL DE CONSTRUÇÕES SUSTENTÁVEIS, 2016, Passo Fundo. Anais... Passo Fundo: IMED, 2016. 
CALORY, Sara Queren Carrazedo. Estudo do uso de contêiners em edificações no Brasil. 2015. 54 p. Trabalho de Conclusão de Curso (Graduação em Engenharia Civil) - Universidade Tecnológica Federal do Paraná. Campo Mourão, 2015.

CARBONARI, Luana Toralles. Reutilização de contêineres ISO na arquitetura: aspectos projetuais, construtivos e normativos do desempenho térmico em edificações no sul do Brasil. 2015. Dissertação (Mestrado de Arquitetura e Urbanismo) - Universidade Federal de Santa Catarina. Florianópolis, 2015.

COLOMBO, Ciliana R.; SATTLER, Miguel Aloysio; ALMEIDA, Marcos Jorge; Bioconstrução: construção do passado ou futuro? In: XI ENCONTRO NACIONAL DE TECNOLOGIA NO AMBIENTE CONSTRUÍDO, 2006, Florianópolis. Anais... 2006.

FERNANDES, Júlia Teixeira. Código de obras e edificações do DF: inserção de conceitos bioclimáticos, conforto térmico eficiência energética. 2009. 249 p. Dissertação (Mestrado em Arquitetura e Urbanismo) - Universidade de Brasília. Brasília, 2009.

FRICKE, Glacir Teresina. Um estudo sobre projeto bioclimáticos e conservação de energia. 1999. 168 p. Tese (Doutorado em Engenharia Mecânica) - Universidade Estadual de Campinas. Campinas, 1999.

GUEDES, Rita; BUORO, Anarrita Bueno. Reuso de containers marítimos na construção civil. Tecnologia e Artística, v. 5, n. 3, p. 101-118, dez. 2015.

HENN, Ana Bell; CALIGARI, Aléssio Inácio. A implantação do telhado verde e sua efetividade. In: V SEMINÁRIO INTERNACIONAL DE CONSTRUÇÕES SUSTENTÁVEIS, 2016, Passo Fundo. Anais... Passo Fundo: IMED, 2016.

JOINVILLE. Secretaria de Informações Municipais Georreferenciadas. Defesa Civil. Disponível em: <https://geoprocessamento.joinville.sc.gov.br/download>. Acesso em: 10 dez. 2018.

JOINVILLE. Secretaria de Planejamento Urbano e Desenvolvimento Sustentável. Joinville bairro a bairro 2017. Disponível em: <https://www.joinville.sc.gov.br/wp-content/uploads/2017/01/Joinville-Bairro-a-Bairro-2017.pdf>. Acesso em: 12 dez. 2018.

LARA, Luiz Carlos. Técnicas de orientação solar no projeto arquitetônico. Disponível em: <http://44arquitetura.com.br/2014/04/tecnicas-de-orientacao-solar-no-projeto/>. Acesso em: 05 fev. 2019.

LEIGHT NETO, Eugênio Henrique. Sustentabilidade das edificações: do projeto à demolição. 2011. 92 p. Dissertação (Mestrado em Engenharia Civil) - Universidade Católica de Pernambuco. Recife, 2011.

MACEDO, Patricia Martins Torres de. Avaliação de sustentabilidade em edifícios: um estudo de indicadores de água e energia na unidade de Fiocruz Pernambuco. 2011. 146 p. Dissertação (Mestrado em Engenharia Civil) Universidade Federal de Pernambuco. Recife, 2011.

MARQUES, Cristian Teixeira; GOMES, Bárbara Maria Fritzen; BRANDLI, Luciana Londero. Consumo de água e energia em canteiros de obra: um estudo de caso do diagnóstico a ações visando à sustentabilidade. Ambiente Construído, Porto Alegre, v. 17, n. 4, p.79-90, out./dez. 2017.

MATTOS, Aldo Dórea. Como calcular consumo de energia e água. Disponível em:<http://blogs.pini.com.br/posts/Engenharia-custos/como-calcular-o-consumo-de-energia-e-agua-3675941.aspx>. Acesso em: 06 maio 2019.

MILANEZE, Giovana Letícia Schindler et al. Utilização de containers como alternativa de habitação social no município de Criciúma/SC. Revista Técnico Científica, v.3, n. 1, p. 615-624, 2012.

MINHA CASA CONTAINER. Pintura de container: dicas e cuidados para se ter uma proteção anticorrosiva e eficiente. Disponível em: <https://minhacasacontainer.com/2015/06/22/pintura-de-container-dicas-e-cuidadospara-se-ter-uma-protecao-anticorrosiva-e-eficiente/>. Acesso em: 06 maio 2019.

NAVROSKI, Marcio Carlos, et al. Avaliação do isolamento térmico de três diferentes materiais usados na construção e preenchimento de paredes externas. Ciência da Madeira, Pelotas, v. 1, n. 1, p. 41-51, maio 2010. 


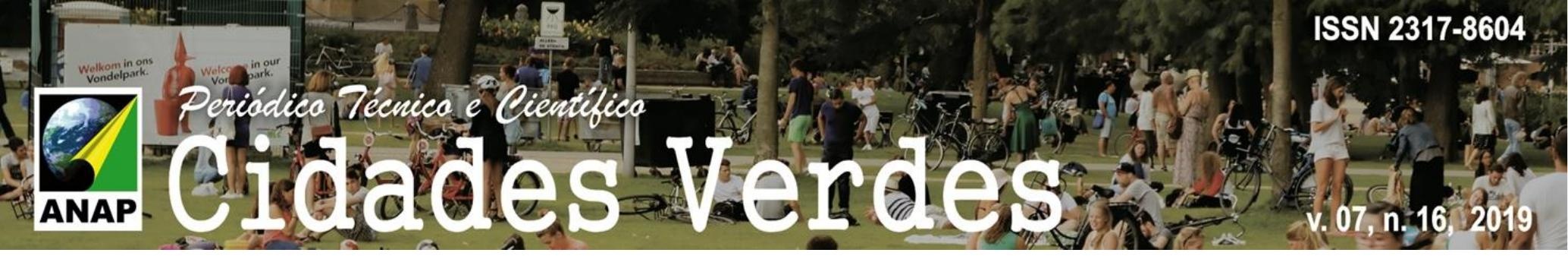

NUNES, Matheus de Araújo; SOBRINHO JUNIOR, Antônio da Silva. Utilização de contêiners na construção civil: estudo de caso. Revista Campo do Saber, 231315, v. 3, n. 2, p.129-151, jul./dez. 2017.

OCCHI, Tailene; ALMEIDA, Caliane Christie Oliveira de. Uso de Containers na Construção Civil: Viabilidade Construtiva e Percepção dos Moradores de Passo Fundo-RS. Revista de Arquitetura, Passo Fundo, v. 1, n. 5, p.1627, 2016.

PATZLAFF, Jeferson Ost. Avaliação da aplicação de princípios da construção sustentável em construtoras de micro e pequeno porte na região do Vale do Caí, RS. 2009. 88 p. Dissertação (Mestrado em Engenharia Civil) Universidade do Vale do Rio dos Sinos. São Leopoldo, 2009.

ROMANO, Leonora; PARIS, Sabine Ritter de; NEUENFELDT JÚNIOR, Alvaro Luiz. Retrofit de contêiners na construção civil. Labor \& Engenho, Campinas, v. 8, n. 1, p.83-92, 2014.

SIQUEIRA, Paula S. Telhados Drancos. Disponível em: <http://fait.revista.inf.br/imagens_arquivos/arquivos_destaque/BpXs8UD6sEI6OPr_2014-4-22-19-52-49.pdf>. Acesso em: 05 fev. 2019. 